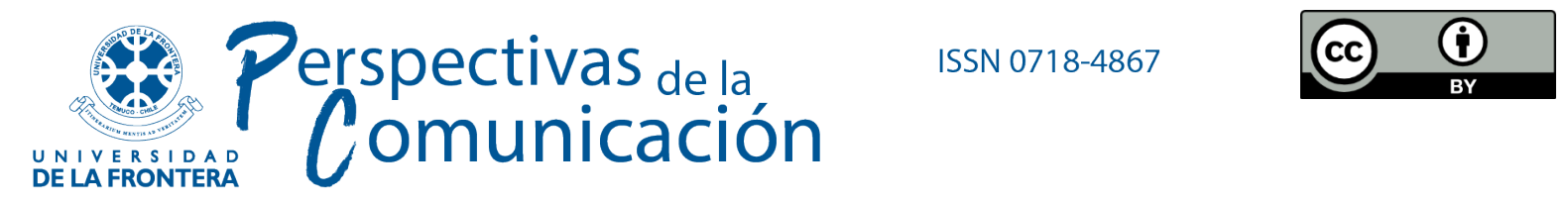

Artículo

\title{
DESINFORMACIÓN Y FACT-CHECKING EN LAS \\ ELECCIONES URUGUAYAS DE 2019. EL CASO DE \\ VERIFICADO URUGUAY
}

DOI: POR ASIGNAR

Dr. Juan Pedro Molina-Cañabate

Universidad Carlos III de Madrid, Madrid, España

juanpedro.molina@uc3m.es

ORCID iD: https://orcid.org/oooo-0002-3665-6656

Dr. Raúl Magallón-Rosa

Universidad Carlos III de Madrid, Madrid, España

raul.magallon@uc3m.es

ORCID iD: https://orcid.org/o0oo-0002-2236-7802

Recibido el 2020-10-21

Revisado el 2021-06-08

Aceptado el 2021-06-08

Publicado el 2021-07-12

\section{Resumen}

El objetivo de esta investigación es estudiar los procesos de desinformación que circularon durante las elecciones presidenciales uruguayas de 2019. Para ello, se ha examinado el trabajo realizado por el proyecto colaborativo de fact-checking Verificado Uruguay. Nuestra investigación establece una tipología de rumores políticos que se propagaron en esta campaña y pretende apuntar su origen y sus motivaciones. Asimismo, demuestra que aunque hay narrativas regionales- los contextos locales hacen que no sea posible establecer paralelismos entre la campaña presidencial de Uruguay y otras de América Latina que se produjeron simultáneamente -como la de Argentina-. Por último, la investigación remarca la importancia del tipo de candidato y de partido o coalición a la hora de incentivar una cultura de la desinformación. 
Perspectivas de la Comunicación

Universidad de La Frontera

Palabras clave: desinformación, elecciones, comunicación, Twitter, redes sociales. 


\title{
DISINFORMATION AND FACT-CHECKING IN THE 2019 URUGUAYAN ELECTIONS. THE CASE OF VERIFICADO URUGUAY
}

\begin{abstract}
The aim of this research is to study the processes of disinformation that circulated during the Uruguayan presidential elections of 2019. To do this, the role of the collaborative project of fact-checking Verificado Uruguay is studied. Our research establishes a typology of political hoaxes that were spread during this campaign and aims to point out their origin and motivations.

It also shows that although there are regional narratives, local contexts make it impossible to establish parallels between the Uruguayan presidential campaign and others in Latin America that occurred simultaneously, such as Argentina. Finally, the research highlights the importance of the type of candidate and party or coalition when it comes to fostering a culture of disinformation.
\end{abstract}

Keywords: misinformation, elections, communication, Twitter, social media. 


\section{Introducción}

Hasta hace poco, el análisis y estudio de los procesos de desinformación en contextos electorales se había centrado principalmente en países anglosajones como EE. UU. (Allcott \& Gentzkow, 2017; Faris et al., 2017) o Reino Unido (House of Commons, 2018), obviando en muchas ocasiones las características sociopolíticas y culturales de cada territorio, así como los distintos factores que intervienen en los procesos de polarización de las campañas electorales.

El objetivo de esta investigación es estudiar los procesos y formas de desinformación que circularon durante las elecciones presidenciales uruguayas de 2019. Para ello, se ha examinado el trabajo realizado por el proyecto colaborativo de fact-checking Verificado Uruguay que integró hasta 127 actores diferentes en la lucha contra la desinformación. La iniciativa pretendía llegar tanto a zonas rurales como a urbanas y diseminar las verificaciones entre el máximo número de fuentes fiables posibles.

En este contexto, resulta pertinente señalar que las elecciones presidenciales uruguayas de 2019 pusieron de manifiesto que el país estaba "dividido en dos fuertes bloques enfrentados" (Martínez, 2019). Por un lado, se presentaba la coalición conservadora, la Coalición Multicolor, encabezada por Luis Lacalle Pou. Por otro, la coalición de izquierdas Frente Amplio, con Daniel Martínez como candidato. La izquierda llevaba gobernando quince años $\mathrm{y}$ aunque los sondeos en primera vuelta fueron positivos para sus intereses, la diferencia se fue reduciendo a medida que se acercaba la fecha del balotaje.

La primera vuelta se celebró el 27 de octubre de 2019. Como ninguno de los dos bloques obtuvo mayoría absoluta fue necesaria una segunda vuelta (conocida en Uruguay como "balotaje"), que tuvo lugar el 24 de noviembre de 2019. Sin embargo, tras el escrutinio inicial de esta segunda vuelta, y aunque Lacalle Pou se posicionó con cierta ventaja de votos (50,79 \% frente al 49,21 \% de Martínez), la situación era de empate técnico.

El país tuvo que esperar hasta el día 28 de noviembre de 2019 para que la Corte Electoral confirmara que Lacalle Pou era el presidente electo de la nación. Lucas Silva (2019) recordaba de esta forma, en The Washington Post, quién era y quiénes formaban parte de la candidatura del nuevo mandatario: "El presidente electo, tercer integrante de su familia que se convierte en jefe de Estado (ya lo fueron el bisabuelo y el padre), asumirá el 1 de marzo de 2020 y gobernará apoyado por una coalición 'multicolor' de cinco partidos, desde el centro 
hasta la extrema derecha. Llegará al poder en su segundo intento y después de una campaña impecable, en la que no cometió errores".

El propio Silva destacaba las siguientes razones para la derrota de la izquierda: la existencia de casos de corrupción, el alejamiento de las políticas sociales, la falta de autocrítica y una campaña electoral "errática y sin una estrategia clara”.

El proceso electoral abrió una etapa con algunas interrogantes: por una parte, se había roto el dominio de la izquierda y, además, la coalición ganadora Partido Nacional albergaba un partido de extrema derecha (Cabildo Abierto).

\section{Método}

El trabajo de análisis se realiza a partir de los 555 tuits publicados por Verificado.uy (@verificadouy) entre el 31 de julio de 2019 y el 25 de noviembre de 2019, un día después de las elecciones celebradas en segunda vuelta. Se amplió el análisis al día posterior para poder comprobar si se generaban bulos y formas de desinformación tras los resultados electorales ${ }^{1}$.

Aunque Verificado Uruguay (2019) hizo publicaciones también en Facebook e Instagram, la recogida de datos se centró en Twitter por la naturaleza pública de la mayoría de sus mensajes y por establecer una mejor medición y codificación con las herramientas de analítica disponibles - gracias entre otras cosas a permitir la descarga de tuits-. En este sentido, los tuits de este estudio fueron descargados a través de T-Hoarder, que trabaja con una metodología denominada t-hoarder_kit, de código abierto, usada desde el año 2012 y que cumple con los requisitos de objetividad, transparencia y compartición de conocimientos (Congosto, Basanta \& Sánchez, 2017).

La labor de análisis se centró en los tuits y en los textos explicativos (post o artículos) publicados en Verificado.uy. Además del texto del tuit, T-Hoarder permite categorizar los tuits por fecha, retuits, me gusta, hashtags o si el tuit va acompañado de imagen o vídeo.

\footnotetext{
${ }^{1}$ Su primer tuit fue publicado el 18 de julio de 2019 y será a partir del 31 de julio cuando se inicie de forma continuada su labor de verificación.
} 
Esta labor se complementó con una entrevista realizada, vía cuestionario, a Ana Matyszczyk, coordinadora y responsable de Verificado.uy y el análisis de los datos internos ofrecidos por la organización para la realización de este trabajo.

Las preguntas de investigación que se plantearon fueron las siguientes:

- ¿Qué tipología de rumores políticos relacionados con las elecciones en Uruguay se puede realizar? ¿Hay diferencias con otros países?

- ¿Qué procedimientos de desmentido tenían desde Verificado Uruguay?

- ¿Hay categorías que sean propias de la cultura política uruguaya y que se alejen de otras tipologías de desinformación previamente identificadas?

- ¿Es posible establecer paralelismos entre los procesos de desinformación y fact-checking que han tenido lugar simultáneamente en otros contextos electorales de América Latina como Argentina?

La hipótesis principal de este trabajo es la siguiente: a la hora de hablar de procesos electorales polarizados es imprescindible remarcar la importancia del tipo de candidato y de partido o coalición a la hora de incentivar una cultura de las fake news, entendida ésta como la creación de un ecosistema de polarización basado en el desarrollo de incentivos económicos, sociales o políticos para generar incertidumbre y falta de confianza durante un proceso electoral (Magallón-Rosa, 2019a). Sin un candidato que busque la polarización como estrategia política, sin un partido que se presente como antiestablishment y sin los incentivos económicos necesarios para que la desinformación tenga beneficios visibles a corto plazo resulta más complicado activar un clima de opinión favorable a este tipo de contenidos.

\section{Marco teórico. De la posverdad a la desinformación.}

En la actualidad, vivimos un momento de normalización de todos los procesos de desinformación en la esfera pública. De este modo, no asistimos sólo a un fenómeno que afecta a la desinformación de carácter político, sino, y quizá más importante, a los bulos relacionados con la inmigración o la ciencia (Molina-Cañabate \& Magallón-Rosa, 2019). En este escenario, la conceptualización de la problemática y las diferentes aristas ha ido evolucionando, pasando por la era de la posverdad o la cultura de las fake news (McIntyre, 2018; Tandoc, Lim \& Ling, 2017) y acabando por establecerse una preferencia y predilección académica e investigadora por el término desinformación en la actualidad. 
$\mathrm{Al}$ respecto, Claire Wardle y Hossein Derakhshan publicaron en septiembre de 2017 un informe con el título El Desorden de la información: Hacia un marco interdisciplinario para la investigación y la formulación de políticas en el que defendían:

\footnotetext{
“Nos abstenemos de utilizar el término ' fake news ` por dos razones. En primer lugar, lamentablemente es inadecuado para describir el complejo fenómeno de la contaminación de la información. El término también ha comenzado a ser apropiado por los políticos de todo el mundo para describir a las organizaciones de noticias cuya cobertura encuentran desagradable. De esta manera, se está convirtiendo en el mecanismo por el cual los poderosos pueden atacar, restringir, socavar y burlar la prensa libre”. (Wardle \& Derakhshan, 2017)
}

Como apuntábamos en la introducción, la evolución del estudio de los rumores y bulos en Twitter y las redes sociales tiene que adaptar narrativas globales a la mirada de cada país y de cada sistema mediático comparado (Hallin \& Mancini, 2004; Humprecht, 2019). En este sentido, la importancia de los debates electorales como momentos clave en los procesos de desinformación coincide y le da una nueva relevancia a la relación que éstos establecen con la agenda mediática.

Hacía más de 25 años que en Uruguay no se desarrollaban debates entre candidatos a la presidencia, por la negativa que manifestaban algunos candidatos en el pasado. El 1 octubre de 2019 se celebró el primer debate de candidatos a la presidencia del siglo XXI y, además, fue el primero en la historia del país que se sometió a la verificación de datos de la mano de Verificado.uy.

\section{Estado de la cuestión. El fact-checking en América Latina.}

El fact-checking es una especialidad basada en la verificación o comprobación de datos a través de la combinación de herramientas digitales y procedimientos periodísticos. De esta forma, se presenta como una respuesta ideada por el periodismo para combatir las falsas informaciones y el incremento de su circulación a través de las redes sociales, con la finalidad de ofrecer a la ciudadanía un relato más ajustado a la realidad (Vázquez-Herrero, Vizoso \& López-García, 2019). Cherubini y Graves (2016) distinguen tres perfiles defact-checkers que -en proyectos colectivos de verificación- se pueden identificar: reporteros, activistas y expertos.

En este sentido, los fact-checkers tienden a proporcionar mayor transparencia en las fuentes cuando los hechos verificados son declaraciones de actores políticos en comparación con declaraciones de actores no políticos (Humprecht, 2019). Desde esta perspectiva, Rodríguez

Perspectivas de la Comunicación - Vol. 14 - No 1 - 2021 - pp. 89-112

Universidad de la Frontera - Chile 
(2019) señala que el fact-checking se guía por cuatro criterios para asegurar la pertinencia de su trabajo:

- La selección del hecho asegurando que se trata de algo factual y no de una opinión, para lo que además se tienen en cuenta los criterios de noticiabilidad (autoría, temática e interés humano), así como su circulación o viralización.

- La selección de fuentes (oficiales, expertas y alternativas) para verificar la información.

- La contextualización del hecho sujeto a comprobación.

- El intento de asignación de una calificación a partir de unas categorías ya preestablecidas (Amazeen et al., 2016).

Para Jane Elizabeth (2014), "la intención de los fact-checkers y de las organizaciones de factchecking es aumentar el conocimiento a través de la investigación y difusión de los hechos recogidos en las declaraciones publicadas o grabadas realizadas por cargos políticos o cualquier otra persona cuyas palabras tengan un impacto en la vida de otros. Los factcheckers investigan los hechos verídicos y su trabajo está libre de intenciones partidistas o de defensa de determinados intereses”.

En América Latina la importancia del fact-checking se ha demostrado fundamental, aunque quedan por medir sus límites, transformaciones y limitaciones. Como recuerdan Vizoso y Vázquez-Herrero (2019), "en el plano geopolítico, es en América del Sur donde podemos encontrar un mayor grado de presencia de las iniciativas de verificación de la información en español” (p. 131). Sin embargo, la evolución de las iniciativas de fact-checking ha seguido un recorrido diferente dependiendo del país, del desarrollo mediático, de los usos digitales y del tipo de verificación (Magallón-Rosa, 2019b).

En este sentido, y hasta la aparición de las iniciativas desarrolladas por First Draft, una organización que impulsa proyectos colaborativos de verificación en todo el mundo Reverso -coordinado por Chequeado-, CrossCheck, Comprova o Comprobado son algunos ejemplos-, el método de organización más frecuente era la integración dentro de un medio de comunicación como sección o la autonomía como medio pero ligada a grupos empresariales con diferentes cabeceras (Vizoso \& Vázquez-Herrero, 2019).

El tipo de noticias más comunes que verificaban eran promesas electorales, entrevistas y debates, declaraciones de políticos y personajes públicos o chequeo/comprobaciones de datos aportados en medios o intervenciones. Sin embargo, cada vez con más frecuencia, 
también se registran verificaciones sobre contenido difundido en redes sociales y propuestas de los usuarios (Vázquez-Herrero, Vizoso \& López-García, 2019).

Según el censo del Duke University Reporters' Lab, existían 44 organizaciones de factchecking en 2014; en noviembre de 2019 -coincidiendo con las elecciones uruguayas- la cifra alcanzaba los $195^{2}$ (Figura 1). En América del Sur, el total de proyectos de verificación era de 27 que se repartían de la siguiente manera:

Figura 1. Número de fact-checkers activos en América del Sur en noviembre de 2019

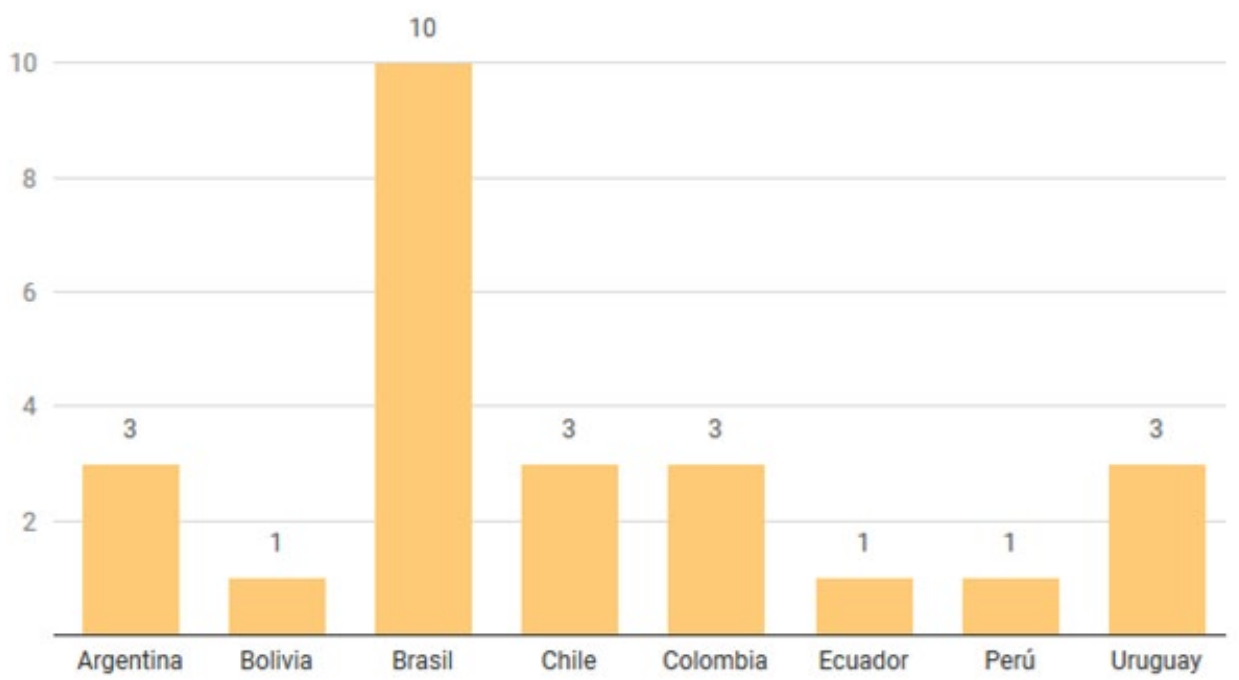

Fuente: Duke Lab.

Desde esta perspectiva, resulta fundamental comprender mejor las condiciones en las que desarrollan estos proyectos colaborativos de verificación con el objetivo de descubrir los factores que hacen que las sociedades sean menos vulnerables a fenómenos como el de la desinformación (Humprecht, Esser \& Van-Aeist, 2020).

\subsection{Verificado Uruguay. El fact-checking colaborativo.}

Como hemos señalado, antes de la experiencia uruguaya, en América Latina se habían dado iniciativas similares en Brasil (Comprova), México (Verificado 2018) o Argentina (Reverso).

\footnotetext{
${ }^{2}$ Véase: https://reporterslab.org/
} 
En este sentido, el proyecto Verificado 2018 en México - referencia de fact-checking colaborativo- tuvo tres ejes de trabajo: detener la viralización de noticias falsas, desmentir la desinformación haciendo verificación de datos del discurso de los candidatos y elaborar “materiales explicativos que ayudaran a prevenir la información falsa" (Nalvarte, 2018).

De Verificado Uruguay formaron parte agencias como AFP o EFE, medios como La Diaria o El País, organizaciones como First Draft, empresas tecnológicas como Facebook o Google, organizaciones de la sociedad civil y universidades. El proyecto se centró en dos tipos de contenidos: rumores y bulos desperdigados en redes sociales y contenidos del discurso público (declaraciones de políticos, aspirantes a puestos de gobierno y gobernantes).

En este sentido, sólo se verificaron contenidos con una interacción significativa en redes sociales. Esta interacción fue medida por la cantidad de post compartidos en Facebook, los retuits en Twitter, etc. Para Ana Matyszczyk,3 responsable de Verificado.uy, la principal característica de esta campaña electoral fue el:

\footnotetext{
"Aumentó significativamente el tráfico de contenido desinformativo, sobre todo a nivel de redes sociales. Es cierto que, como dice el dicho, el que busca encuentra. Lo que significa que, también, el hecho de rastrear rumores por el mundo digital asegura que se encuentre mayor cantidad contenido engañoso, que si no se busca. De todas formas, personalmente creo que esta campaña presentó ambos elementos: la novedad de tener monitoreada esta realidad y, además, una novedad cultura dañina que pretende utilizar las redes sociales para propagar mentiras".
}

Para Fregoso (2018), con el auge de los medios digitales independientes, "muchos lectores comienzan a dudar de la calidad e imparcialidad de la información publicada por los periódicos, pero también hay millones de jóvenes lectores nuevos para quienes la información impresa ya no es relevante”. El objetivo del proyecto Verificado Uruguay era crear una marca de confianza que alcanzara perfiles muy diversos. Para Ana Matyszczyk coordinadora y responsable de Verificado Uruguay:

"Lo que nos imaginamos antes de empezar a trabajar [el volumen de desinformaciones] tampoco ocurrió. Si bien hubo mayores índices de desinformación que en otras campañas anteriores, nosotros imaginamos que nos enfrentaríamos a un caudal mayor. Pero la realidad es que Uruguay es un país

\footnotetext{
${ }^{3}$ Entrevista personal. Respuesta por cuestionario el 10 de diciembre de 2019.
} 
pequeño, de 3.500.00o habitantes aproximadamente, y el flujo está acorde a esta dimensión, a diferencia de la cantidad de desinformación que puede, por ejemplo, circular en Brasil, donde viven más de 200 millones de personas. Eso no quita que en Uruguay existe una necesidad latente por mitigar el impacto negativo que produce este fenómeno y es de una urgencia mayúscula diseñar iniciativas como la de Verificado.uy para defender la calidad de la información que reciben los uruguayos".

Verificado.uy, además de trabajar con el rastreo de contenidos de desinformación en redes sociales, también abordó la verificación de los discursos públicos correspondientes a los candidatos presidenciales, únicamente, en las instancias de debate televisivo. Es decir que no verificaron lo que habían dicho los candidatos en cada acto o en entrevistas periodísticas, sino que su universo de trabajo se redujo, exclusivamente, a las instancias de debate.

Otro de los resultados del análisis que se presenta tiene que ver con el poder de las imágenes trucadas. En el proceso electoral uruguayo, Verificado.uy encontró imágenes falsas, manipuladas o/y sacadas de contexto. La entidad verificadora utilizó la técnica de "búsqueda inversa" en buscadores y se ayudó de herramientas como InVid, Who posted that o, incluso, Google Street View. En este sentido, hubo veces en las que una misma imagen, tomada en España, por ejemplo, se había utilizado en Argentina atribuyéndole un contexto distinto y, después, se utilizó también en Uruguay con otro contexto (falso) diferente. Es decir, los bulos (o, al menos, un tipo de bulos relacionados con las imágenes) pueden ser transnacionales y adaptados a ciertas estrategias de desinformación.

Entre las tipologías de verificaciones realizadas por Verificado Uruguay destacan:

- - Alfabetización y proceso electoral

- $\quad$ - Fraude electoral

- - Informaciones descontextualizadas o engañosas

- - Declaraciones falsas

- - Apoyo de celebrities

- - Informaciones falsas

- - Imágenes o vídeos falsos

Como señala Matyszczyk, desde la coalición se conformaron mesas temáticas en torno a los cuatro ejes claves de campaña: economía, seguridad, educación y desarrollo social. Se convocaron investigadores de todas las universidades y técnicos profesionales, además de periodistas especializados en cada área y los periodistas de la redacción de Verificado.uy. Los participantes vieron el primer debate todos juntos desde las instalaciones de La Diaria, un diario uruguayo que dispone de instalaciones lo suficientemente grandes para recibir casi 
60 personas y comenzaron a trabajar. Algo similar sucedió en el segundo debate entre candidatos a la presidencia, en el mes de noviembre, de cara al balotaje o segunda votación. Por lo tanto, con Verificado Uruguay se creó un primer antecedente también en este nivel de cobertura, el discurso público.

\subsection{Verificado Uruguay $y$ Reverso Argentina. Magnitudes (no) comparables.}

Poco antes de los comicios en Uruguay, tuvieron lugar (el 27 de octubre de 2019) las, hasta la fecha, últimas elecciones presidenciales en Argentina. Los resultados políticos tuvieron similitudes en ambas citas con las urnas (Gallo, 2018a, 2018b).

En Argentina ganó el peronismo de la mano de Alberto Fernández (del Partido Justicialista, perteneciente de la coalición Frente de Todos). Cristina Fernández volvía a la primera línea de la política postulándose, dentro de esta coalición, como vicepresidenta del Gobierno. La coalición Frente de Todos obtuvo el 48,10 \% de los votos. El expresidente Mauricio Macri, del partido Propuesta Republicana (de la alianza Juntos por el Cambio) obtuvo el 40,37 \% de los votos (Molina-Cañabate, Magallón-Rosa \& Paniagua, 2020).

Como señaló Alconada (2019), "según miembros de equipos de campaña que consulté, esta será también una de las campañas más sucias desde el retorno de la democracia en el país, en 1983”. El posible escenario de desinformación que se empezó a dibujar ya tenía precedentes. Entre otras razones porque las elecciones presidenciales argentinas de 2015 ya se vieron salpicadas con el escándalo de Cambridge Analytica.

En este contexto, una de las particularidades de los bulos que circularon en Argentina es que fueron reseñables los relacionados con la mala gobernanza (Molina-Cañabate, MagallónRosa \& Paniagua, 2020): apagones, autopistas mal construidas, puentes, calles inundadas, trenes descarrilados, etc., mientras que en Uruguay parte del debate de los datos estaba en su posición el índice de desarrollo humano en Latinoamérica, sueldos o datos comparando el país en 2004 con los datos de 2019.

En Uruguay, como hemos visto anteriormente, tras quince años de gobiernos de izquierdas, la coalición conservadora encabezada por el Partido Nacional (encabezada por Luis Lacalle Pou) ganó al izquierdista Frente Amplio, con Daniel Martínez como candidato. Al igual que 
en Argentina, la división del voto era clara. El "descontento generalizado" se presentaba como una variable a analizar (Caetano, Selios \& Nieto, 2019).

Periodísticamente, las entidades verificadoras Reverso (en Argentina) y Verificado (en Uruguay) esperaban encontrarse en campaña política un incremento notable de informaciones falsas. Con todos los matices que supone equiparar la cantidad de publicaciones con el volumen de desinformación es importante señalar que, desde Reverso, se llegaron a publicar 169 verificaciones nuevas frente a las 57 categorizadas por Verificado Uruguay.

Para Ana Matyszczyk, responsable de Verificado Uruguay:

"A grandes rasgos puedo decirte que hay un tema de escala y otro cultural. Ellos son 40 millones de habitantes y nosotros poco más de 3 millones. La grieta social que divide a las diferentes posturas políticas en Argentina es significativamente mayor a la que existe en Uruguay, y esa distancia, sumado a particularidades de la cultura propia de Argentina, intuyo que puede afectar el tipo de desinformación que circula en un país y en otro”.

\section{Resultados}

Un análisis de las métricas que ofrece Twitter puede dar pistas, huellas e indicios sobre transformaciones sociales, pero también dibujar tendencias y patrones sociológicos muy significativos para el objeto de estudio (Márquez-Domínguez, López-López \& Arias, 2017). La descarga de los tuits de la cuenta de Verificado Uruguay da la posibilidad de conocer la fecha y hora de publicación de un tuit, el contenido, el enlace al propio tuit, el número de seguidores de la cuenta, el idioma, el número de retuits y el número de Me Gusta.

Como hemos señalado, el trabajo de análisis se realizó a partir de los 555 tuits publicados por Verificado.uy entre el 31 de julio de 2019 y el 25 de noviembre de 2019 (Figura 2), un día después de las elecciones celebradas en segunda vuelta. 
Figura 2. Porcentaje de distribución por mes del número de tuits publicados por Verificado.uy

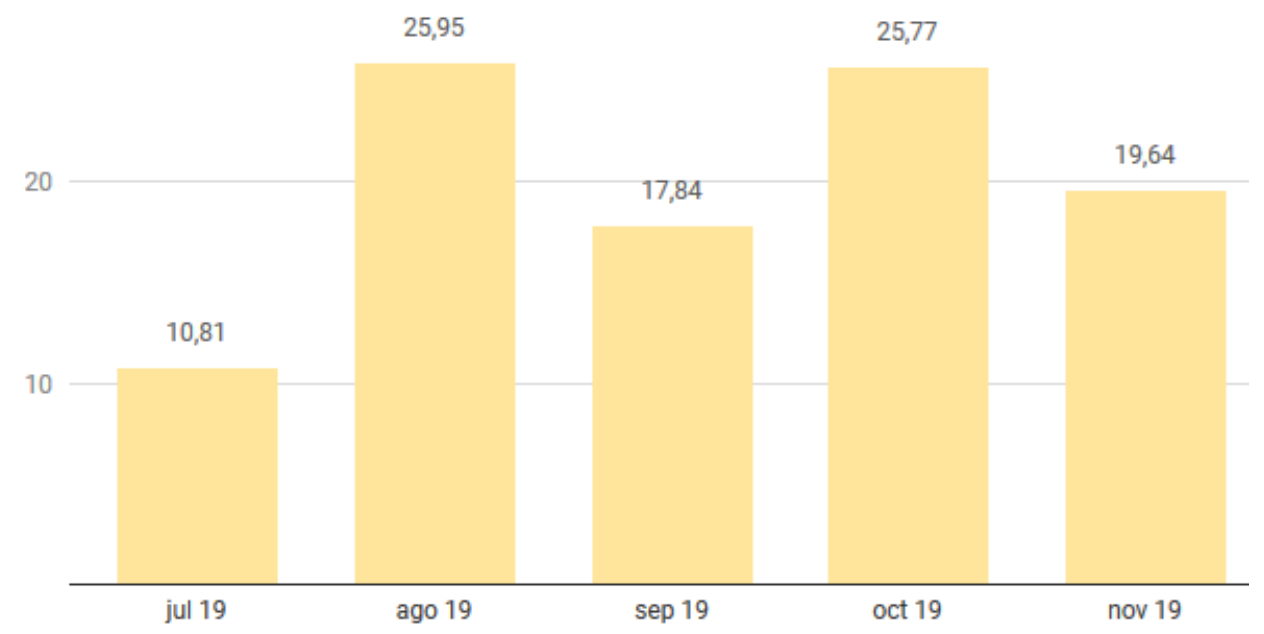

Fuente: Elaboración Propia

En primer lugar, hemos de señalar que no se observa un incremento en la publicación de tweets por parte de Verificado Uruguay a medida que se acercan las elecciones. De hecho, el mes de agosto supone una cuarta parte del tráfico informativo. Del total de 555 tuits analizados aparecieron -eliminando los repetidos- 57 con la etiqueta Nuevo.

Sin embargo, sí se puede comprobar que hay un incremento notable de desmentidos y bulos verificados en los meses de octubre y noviembre a medida que se acerca la campaña electoral y la fecha de los comicios (Figura 3). 
Figura 3. Porcentaje de distribución mensual de los desmentidos y verificaciones realizadas por Verificado Uruguay

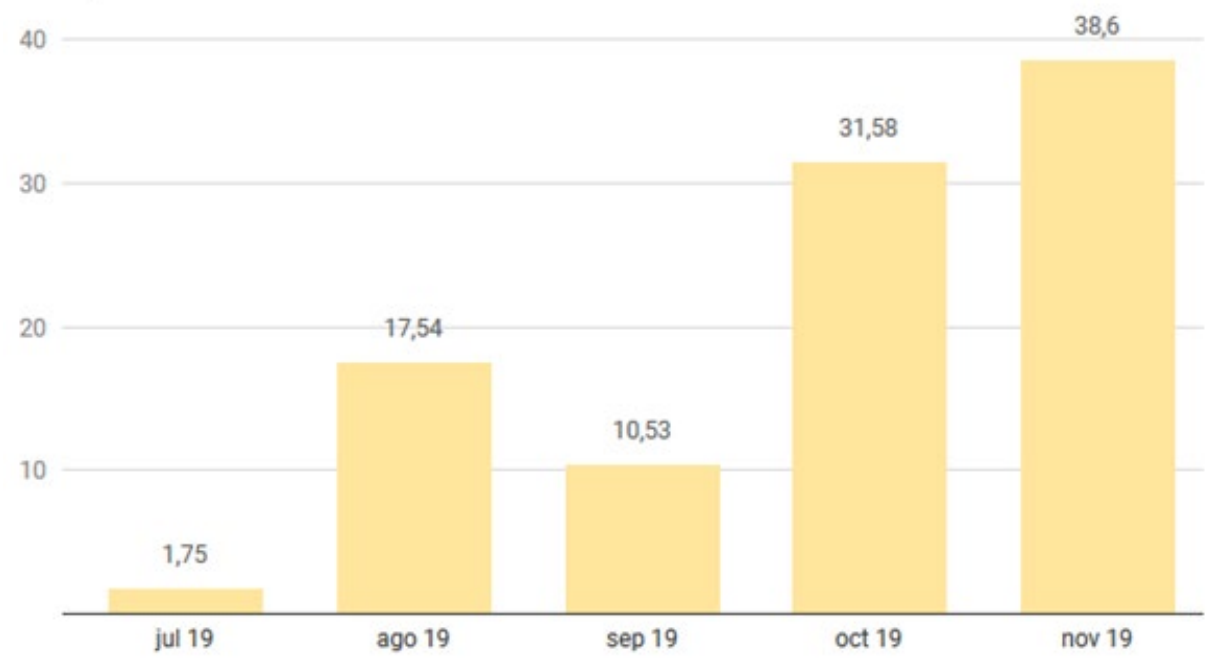

Fuente: Elaboración propia.

$\mathrm{El} \mathrm{70,2} \mathrm{\%} \mathrm{de} \mathrm{las} \mathrm{verificaciones} \mathrm{fueron} \mathrm{hechas} \mathrm{durante} \mathrm{los} \mathrm{meses} \mathrm{de} \mathrm{octubre} \mathrm{y} \mathrm{noviembre} \mathrm{de}$ 2019. Como hemos apuntado, destacan las verificaciones realizadas durante los debates entre los candidatos Daniel Martínez y Luis Lacalle Pou (el 1 de octubre de 2019 y el 14 de noviembre de 2019).

Es ahí donde el papel de Verificado.uy fue más visible con titulares como:

- "Es falso que en 2005 el desempleo haya sido del 20\%, como afirmó Martínez".

- "Es falso que hoy sólo $27 \%$ de los niños y 8,8\% de las embarazadas estén correctamente controlados en ASSE, como afirmó Lacalle Pou".

Para contrastar estas informaciones, la entidad verificadora uruguaya acudió a datos oficiales. Por ejemplo: "El candidato oficialista Daniel Martínez se refirió a la situación del empleo durante el bloque economía del debate presidencial y aseguró que, en 2005, cuando el Frente Amplio (FA) llegó al gobierno, la desocupación era del 20 \% de la Población Económicamente Activa (PEA). Esa afirmación es falsa: el desempleo promedio en ese año se ubicó en el 12.2 \% de la PEA, según los datos del Instituto Nacional de Estadística (INE)”.

En cuanto a las fuentes de las que provienen los bulos, vemos que son muy diversas. Observamos un abanico que abarca desde usuarios desconocidos que propagan mensajes en WhatsApp hasta los propios candidatos presidenciales (como hemos visto más arriba), 
pasando por cuentas de Twitter falsas que luego se borran, usuarios de Twitter escondidos tras un nick anónimo, también usuarios de redes sociales con identidad real dudosa, una serie de televisión, páginas de Facebook o, incluso, páginas web ya cerradas, de las que hoy sólo podemos consultar su versión caché.

También se pudieron identificar usuarios desconocidos que propagan mensajes en WhatsApp y que son, por ejemplo, quienes hicieron circular la información falsa de que ciertas papeletas con errores de imprenta no serían contadas como válidas.

Usuarios desconocidos también estuvieron detrás de un supuesto tuit que escribió el candidato del Frente Amplio, Daniel Martínez, que luego supuestamente borró. A algunos usuarios de Twitter les dio tiempo -en teoría- de hacer una captura de pantalla de ese tuit. Verificado.uy comprobó que nunca se escribió ese mensaje. "Varias publicaciones en Facebook y Twitter aseguran que el candidato del Frente Amplio (FA), Daniel Martínez, publicó y luego borró un tuit en el que le pedía a sus votantes que dejen de escuchar al cantante Lucas Sugo, por haber participado en un acto del Partido Nacional. Sin embargo, el tuit es un montaje que se obtuvo tras alterar el código HTML de una publicación de Martínez [...] La imagen comenzó a viralizarse el pasado 10 de noviembre a través de una cuenta luego eliminada".

La incapacidad de controlar un bulo fue constatada por Verificado.uy ya que el tuit falso mencionado derivó en otros fakes o contenidos falseados. Verificado.uy lo explica así:

\footnotetext{
"Luego de la viralización del falso tuit sobre Lucas Sugo, circularon otras supuestas capturas de tuits de Martínez, ya en clave de humor. "Así, se pudo ver una imagen en la que el candidato oficialista supuestamente realiza comentarios soeces contra quienes divulgaron la falsa publicación $(1,2)$, otra en la que insulta a la barra brava (ultras) del Club Nacional de Football, uno de los equipos más importantes del país, y una más en la que desafía a su rival. Incluso se sumó un falso tuit de Lacalle Pou diciendo que estará reloco".
}

Algunos bulos son firmados por usuarios de Twitter con nombres y apellidos reales, quienes, desgraciadamente, se hacen portadores, a su pesar, de una información descontextualizada porque tiempo después su mensaje se saca de contexto. Es el caso, por ejemplo, de un usuario argentino, que en febrero denunciaba en Twitter el fraude electoral informático en su país, pero alguien viralizó sus palabras como si fuera uruguayo y hubieran sido enunciadas en octubre. 
Verificado.uy también investigó informaciones falsas de páginas web, como integracionteerritorial.org, de las que hoy sólo podemos consultar su versión caché.

De los resultados de nuestro estudio, queremos subrayar que de las 57 informaciones verificadas por Verificado.uy destaca que más de 54 \% hacen referencia a informaciones, vídeos o imágenes falsas y cerca del 25\% son contenidos sobre alfabetización y verificación de informaciones políticas (Figura 4). Esta distinción nos permite comprender las dinámicas internas de funcionamiento en la verificación del proyecto colaborativo.

Figura 4. Porcentaje del tipo de verificaciones realizadas por Verificado.uy

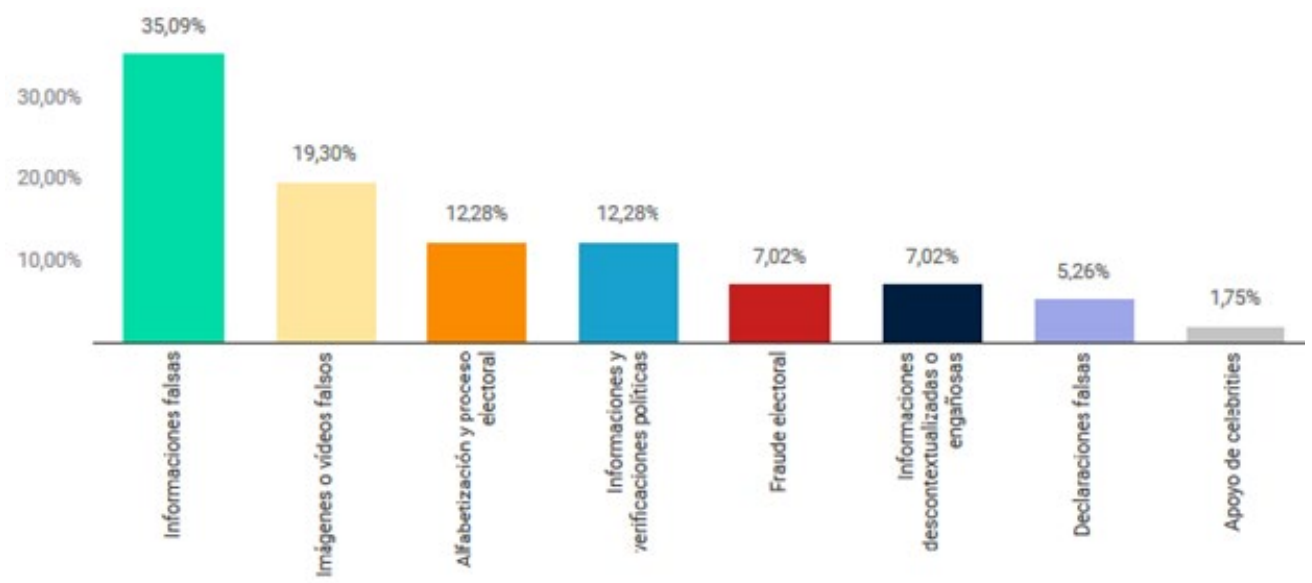

Fuente: Elaboración propia

Por otra parte, resultaba importante monitorizar las fuentes de intermediación de los contenidos falsos. Entre los canales de distribución de los bulos o informaciones falsas destacan: las declaraciones con datos falsos en los debates, Facebook, Twitter o WhatsApp -ésta última destaca por la complejidad de monitorización si no es a través de consultas ciudadanas- (Figura 5). En ocasiones, las comprobaciones de Verificado Uruguay se monitorizan y aparecen por diferentes redes sociales y en otras ocasiones no se explicita el tipo de red o plataforma de procedencia 4 .

\footnotetext{
${ }^{4}$ Nuestro análisis se basa únicamente en aquellas fuentes perfectamente identificadas en los contenidos verificados por parte de Verificado $U Y$.
} 
Figura 5. Distribución por canales de procedencia del tipo de verificaciones realizadas por Verificado.uy

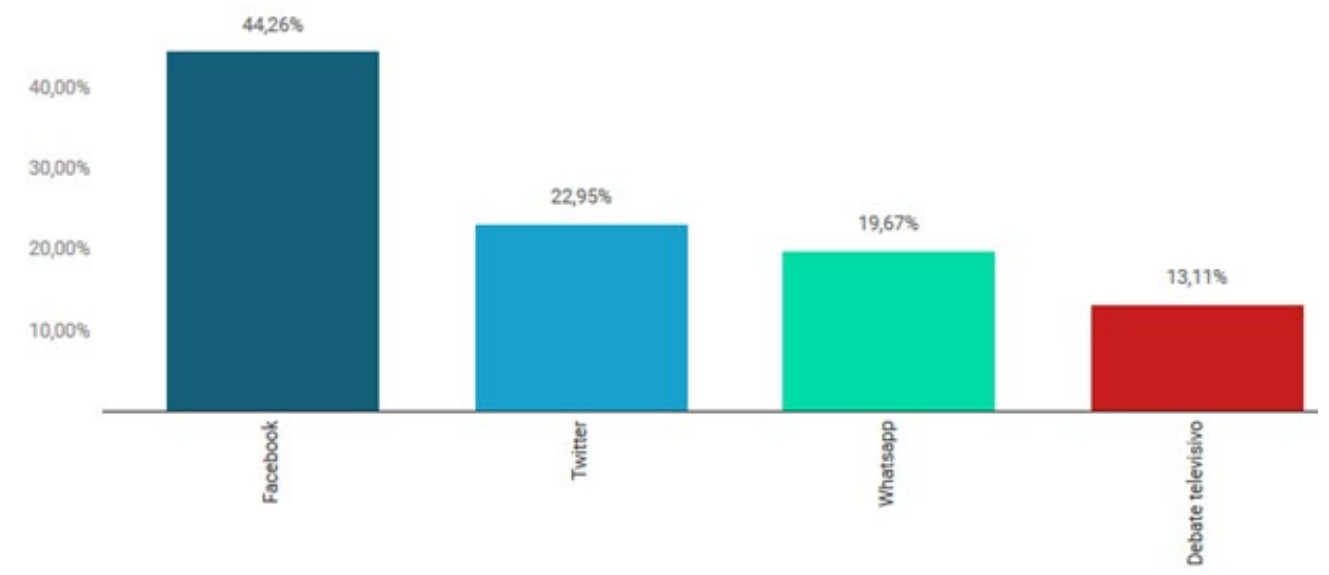

Fuente: Elaboración propia

En cualquier caso, es importante destacar que Facebook se convirtió en el canal preferente para la difusión de esta campaña desde un punto de vista de la verificación, alcanzando casi el $44 \%$ de las informaciones categorizadas, por encima de Twitter (22,95 \%) y WhatsApp $(19,67 \%)$.

\section{6.- Discusión}

Como señalábamos en la introducción, a la hora de hablar de procesos electorales polarizados es imprescindible remarcar la importancia del tipo de candidato y de partido o coalición a la hora de incentivar una cultura de la desinformación. Sin un candidato que busque la polarización como estrategia política, sin un partido que se presente como antiestablishment y sin los incentivos económicos necesarios para que la desinformación tenga beneficios visibles a corto plazo resulta más complicado activar un clima de opinión favorable a este tipo de contenidos.

$\mathrm{Al}$ respecto, el escenario de incertidumbre en el resultado electoral no generó un clima de desinformación significativo puesto que los dos candidatos no apostaron por la polarización y la división como estrategia principal de campaña. Resulta imprescindible, en este sentido, destacar -según los datos de Verificado Uruguay- el papel de Facebook como canal 
preferente en la difusión de desinformación en esta campaña, alcanzando casi el 44\% de las verificaciones categorizadas.

En el caso de Uruguay, a diferencia de países como México, no se ha demostrado que existiera un ecosistema mediático alternativo que pudiera desarrollar un clima de duda e incertidumbre ni agentes externos interesados en influir de forma evidente en la estabilidad del país.

Si parece pertinente señalar que los verificadores, en este sentido, se han incorporado a las dinámicas de poder y contrapoder de la esfera pública y se presentan como un agente informativo incómodo para aquellos actores que pretenden reducir la intermediación del discurso político de los medios de comunicación.

Desde esta perspectiva es importante seguir analizando cómo - a pesar de que hay determinadas estructuras narrativas que permiten hacer una tipología de bulos a nivel global- resulta imprescindible entender que cada país tiene sus propias formas de desinformación culturales y sociales.

En este sentido, no se pueden comparar la importancia de la desinformación en elecciones próximas en el tiempo y en la geografía como fueron las de Uruguay y Argentina, porque se trata de dos países con unas dimensiones, un ecosistema informativo y una cultura política diferente.

Como hemos podido comprobar, no se observa un incremento en la publicación de tweets por parte de Verificado Uruguay a medida que se acercan las elecciones. Si bien se puede verificar que hay un incremento notable de desmentidos y bulos verificados en los meses de octubre y noviembre a medida que se acerca la campaña electoral y la fecha de los comicios, llegando hasta el $70 \%$ del total de contenidos verificados y publicados.

Como novedad narrativa de Verificado.uy destaca el uso de Instagram como plataforma de difusión de las verificaciones publicadas, con imágenes y vídeos de alfabetización, así como herramienta de aproximación a otro tipo de perfiles menos politizados.

De nuestro análisis queremos subrayar la necesidad de que este tipo de plataformas colaborativas de fact-checking, como el caso de Verificado.uy, decidan previamente las categorías internas con las que van a trabajar para poder encontrar patrones de 
comportamiento de los bulos y los procesos de desinformación pero también para que posteriormente esos datos puedan ser puestos a disposición de la comunidad académica para completar las investigaciones que se están desarrollando sobre un fenómeno como es el de la desinformación que está integrándose en todos los espacios de la esfera pública.

Desde el punto de vista de la transparencia -medida mediante la aparición de enlaces a documentos o fuentes externas- resulta fundamental establecer una serie de categorías que permitan establecer un método de rendición de cuentas en torno a los diferentes ítems: el enlace a sitios de noticias, gráficos, tablas, imágenes u otras fuentes, etc.

Como conclusión queremos señalar que es muy complicado para la ciudadanía, en el contexto actual, afrontar un proceso electoral sin la labor de entidades de verificación. Entre otras razones porque cada vez es más difícil explicar la geopolítica y la economía sin las estrategias de desinformación que se interrelacionan, pero también sin comprender los canales y tipos de desinformación que circulan de manera local.

\section{Agradecimientos o reconocimientos}

Este proyecto forma parte de la investigación "Knocking down fake news: Analysing Factchecking journalism processes and effects” de la Universidad de Ibagué (Colombia).

\section{Conflicto de interés}

Los autores declaran que no existe conflicto de interés. 


\section{Referencias bibliográficas}

ALCONADA, H. (1 de abril 2019): ¿Cómo combatir las noticias falsas durante las elecciones en Argentina? The New York Times. https://www.nytimes.com/es/2019/04/o1/fake-newsargentina-macri-cristina

ALLCOTT, H. \& GENTZKOW, M. (2017): Social media and fake news in the 2016 election. Journal of Economic Perspectives, 31(2), pp. 211-236.

https://www.nber.org/papers/w23089

AMAZEEN, M. A., THORSON, E., MUDDIMAN, A. \& GRAVES, L. (2016): Correcting Political and Consumer Misperceptions: The Effectiveness and Effects of Rating Scale Versus Contextual Correction Formats. Journalism \& Mass Communication Quarterly, 95(1), pp. 28-48. https://doi.org/10.1177/1077699016678186

CAETANO, G., SELIOS, L. \& NIETO, E. (2019): Descontentos y “cisnes negros": las elecciones en Uruguay en 2019. Araucaria, 21(42).

https://revistascientificas.us.es/index.php/araucaria/article/view/10792

CHERUBINI, F. \& GRAVES, L. (2016): The rise of fact-checking sites in Europe. Reuters Institute of Journalism. University of Oxford. https://ora.ox.ac.uk/objects/uuid:d55ef650e351-4526-b942-6c9eoo129ad7

CONGOSTO, M., BASANTA, P. \& SÁNCHEZ, L. (2017): T-Hoarder: A framework to process Twitter data streams. Journal of Network and Computer Applications, 83, pp. 28-39. https://doi.org/10.1016/j.jnca.2017.01.029

ELIZABETH, J. (20 de mayo 2014): Who are you calling a fact checker? American Press Institute. https://www.americanpressinstitute.org/fact-checking-project/fact-checkerdefinition/

FARIS, R. M., ROBERTS, H., ETLING, B., BOURASSA, N., ZUCKERMAN, E. \& BENKLER, Y. (2017): Partisanship, Propaganda, and Disinformation: Online Media and the 2016 U.S. Presidential Election. DASH.HARVARD.EDU.

https://dash.harvard.edu/bitstream/handle/1/33759251/2017-08 electionReport 0.pdf

Perspectivas de la Comunicación - Vol. 14 - No 1 - 2021 - pp. 89-112

Universidad de la Frontera - Chile 
FREGOSO, J. (2018): \#Mexico2018|'Fake News' and Social Media: The New Heads of the Hydra. Reuters Institute of Journalism. University of Oxford.

https://reutersinstitute.politics.ox.ac.uk/sites/default/files/2018-

o6/Mexico2018\%20Fake\%20News\%20and\%20Social\%2oMedia\%20The\%2oNew\%20Hea ds\%20of\%2othe\%20Hydra $0 . p d f$

GALLO, A. (2018b): Un prolongado ciclo eleccionario. Análisis de la aplicación conjunta de primarias abiertas y doble vuelta electoral en los últimos comicios presidenciales en Argentina y Uruguay. Apuntes Electorales: revista del instituto electoral del estado de México, 17(58), pp. 11-59. https://dialnet.unirioja.es/servlet/articulo?codigo=6426386

(2018a): Internas abiertas reguladas y buen funcionamiento partidario: Los casos actuales de Argentina y Uruguay. Espiral: Estudios sobre Estado y Sociedad, 25(72), pp. 3781. https://dialnet.unirioja.es/servlet/articulo?codigo $=6543395$

HALLIN, D. C. \& MANCINI, P. (2004): Sistemas mediáticos comparados. Tres modelos de relación entre los medios de comunicación y la política. Cambridge, Cambridge University Press.

HOUSE OF COMMONS (2018): Disinformation and "fake news": Interim report, fifth report of session 2017-2019. www.parliament.uk

https://publications.parliament.uk/pa/cm201719/cmselect/cmcumeds/363/363.pdf

HUMPRECHT, E. (2019): How do they debunk "fake news? A cross-national comparison of transparency in fact checks. Digital Journalism, 8(3), pp. 310-327.

https://doi.org/10.1080/21670811.2019.169103

HUMPRECHT, E., ESSER. F. \& VAN-AEIST, F. (2020): Resilience to Online Disinformation: A Framework for Cross-National Comparative Research. The International Journal of Press/Politics, 25(3), pp. 493-516. https://doi.org/10.1177/1940161219900126

MAGAllón-ROSA, R. (2019a): Unfaking News. Cómo combatir la desinformación. Madrid, Ediciones Pirámide. 
(2019b): Verificado México 2018. Desinformación y fact-checking en campaña electoral. Revista de Comunicación, 18(1), pp. 234-258. https://doi.org/10.26441/RC18.12019-A12

MÁRQUEZ-DOMÍNGUEZ, C., LÓPEZ-LÓPEZ, P. C. \& ARIAS, T. E. (o1 de junio 2017): Social networking and political agenda: Donald trump's Twitter accounts [Sesión de Conferencia]. 12th Iberian Conference on Information Systems and Technologies (CISTI), Lisbon, Portugal. https://doi.org/10.23919/CISTI.2017.7976052

MARTÍNEZ, M. (28 de noviembre 2019): La Corte Electoral da la victoria por la mínima a Lacalle Pou en las presidenciales de Uruguay. El País. https://elpais.com/internacional/2019/11/28/actualidad/1574958210 943004.html

MCINTYRE, L. C. (2018): Post-truth. Cambridge (Massachusetts), The MIT Press.

MOLINA-CAÑABATE, J. P. \& MAGALLÓN-ROSA, R. (2019): Procedimientos para verificar y desmontar informaciones falsas basadas en el discurso del odio. El caso de Maldita Migración. Revista Asociación Española de Investigación en Comunicación, 6(12), pp. 95122. http://www.revistaeic.eu/index.php/raeic/article/view/204/176

MOLINA-CAÑABATE, J. P., MAGALLÓN-ROSA, R. \& PANIAGUA, F. J. (2020): Desinformación y fact-checking en las elecciones argentinas de 2019. El caso de la iniciativa Reverso. Revista de Estilos de Aprendizaje, 13(26), pp. 33-49.

http://revistaestilosdeaprendizaje.com/article/view/2161

NALVARTE, P. (3 de julio 2018): Colaboración de medios y aporte ciudadano impulsaron fact-checking de Verificado 2018 durante elecciones mexicanas. Knight Center for Journalism in the Americas. https://knightcenter.utexas.edu/es/blog/oo-19905colaboracion-de-medios-y-aporte-ciudadano-impulso-fact-checking-de-verificado-2018$\underline{\text { dur }}$

RODRÍGUEZ, C. (2019): No diga fake news, di desinformación: Una revisión sobre el fenómeno de las noticias falsas y sus implicaciones. Comunicación, (40), pp. 65-74. https://dialnet.unirioja.es/servlet/articulo?codigo $=7028909$ 
SILVA, L. (29 de noviembre 2019): Uruguay: el Frente Amplio perdió la batalla por el sentido común (y las elecciones). The Washington Post. https://www.washingtonpost.com/es/postopinion/2019/11/29/uruguay-el-frente-amplio-perdio-la-batalla-por-el-sentido-comun-ylas-elecciones/

TANDOC, E., LIM, Z. \& LING, R. (2017): Defining “fake news". Digital Journalism 6(2), pp. 137-153. https://www.tandfonline.com/doi/abs/10.1080/21670811.2017.1360143

VÁZQUEZ-HERRERO, J., VIZOSO, Á. \& LÓPEZ-GARCÍA, X. (2019): Innovación tecnológica y comunicativa para combatir la desinformación: 135 experiencias para un cambio de rumbo. El profesional de la información, 28(3), pp. 1-12.

https://doi.org/10.3145/epi.2019.may.01

VERIFICADO (2019): Tu escudo contra la desinformación. Verificado. https://verificado.uy

VIZOSO, A. \& VÁZQUEZ-HERRERO, J. (2019): Plataformas de fact-checking en español. Características, organización y método. Communication \& Society, 32(1), pp. 127-144. https://dadun.unav.edu/handle/10171/57837

WARDLE, C. \& DERAKSHAN, H. (2017): Information Disorder: Toward an interdisciplinary framework for research and policy making. Council of Europe. https://rm.coe.int/information-disorder-toward-an-interdisciplinary-framework-forresearc/168076277c 